\title{
Power compensation for vector-based current control of a modular multilevel converter (MMC) based STATCOM
}

\author{
A. U. Lawan ${ }^{1}$, S. Babani ${ }^{2}$, A. Abdulkarim ${ }^{3}$, G. S. Shehu ${ }^{4}$, Y. Jibril M, ${ }^{5}$ I. S. Madugu ${ }^{6}$ \\ ${ }^{1}$ Department of Electrical \& Electronic Engineering, University of Nottingham, Malaysia. \\ ${ }^{2}$ Department of Electrical Engineering, Bayero Univeristy Kano, 10 Gwarzo Road, Nigeria \\ 3,4,5 Department of Electrical Engineering, Ahmadu Bello Univeristy Zaria, Nigeria. \\ ${ }^{6}$ Department of Electrical Engineering, Kano University of Science and Technology, Nigeria
}

\begin{abstract}
Article Info
Article history:

Received Mar 21, 2019

Revised Apr 21, 2019

Accepted Jun 20, 2019

Keywords:

d-q power algorithm

DSTATCOM

Power quality (PQ)

Universal power quality

conditioner (UPQC)
\end{abstract}

\begin{abstract}
This paper studies the suitability of a vector based current control which is mostly employed for its faster response in the reactive current applications of static compnesators (STATCOMs). The current control is mostly achieved using proportional-integral (PI) controllers because of the advantage of their good tracking and small variations. However, due to the dependency of PI controllers on the modular multilevel converter (MMC) system dynamics, performance variations arise during steady-state STATCOM non-ideal operations. This paper presents an improved MMC based STATCOM control with a d-q compensation algorithm added to the vector based current control. The algorithm is derived to tackle the effects of the dynamics of the MMC and the STATCOM ideal variations without the use of any additional controller. The control is achieved by providing a power compensation in the d-q axis which injects currents at the input of the PI controllers in order to improve the steady-state performance of the STATCOM control.
\end{abstract}

Copyright (C) 2019 Institute of Advanced Engineering and Science. All rights reserved.

\section{Corresponding Author:}

Abdurrahman Umar Lawan, Departement of Electrical Engineering, University of Nottingham, Malaysia Campus, 43500 Semenyih. Malaysia

E-mail:kecx4aua@nottingham.edu.my

\section{INTRODUCTION}

Power quality can be affected by many types of disturbances which can affect or precisely reduce grid power performance [1]. Depending on the issues arising such as distortions, voltage transients, sags, flickers, swells, unbalances among voltages, and interruptions. Custom power devices (CPDs) technology has been used to mitigate power problems and improve power quality (PQ) [1-3]. Some of these devices such as the univer $\neg$ sal power quality conditioner (UPQC), static compensator (STATCOM), and dynamic voltage restorer (DVR) can be implemented in voltage source multilevel converters (VSMCs) topologies [4-6]. Shunt devices such as STATCOM which is applied in distribution grids called distribution static compensator (DSTATCOM) exists, it's mainly for reactive power compensation, flicker mitigation, voltage regulation, harmonic filtering, and load voltage balancing. There are series connection devices[7], typical one is dynamic voltage restorer (DVR) commonly used for stabilization of voltage for critical end users. DVR normally comes with an energy facility for storage and short voltage-dip control or short loss of a generation plant from the power network source [7]. Also, there are combined shunt and series connection devices such as univer $\neg$ sal power quality conditioner (UPQC) [8,9] that can be employed. Electric drives such as driving pumps, high-power consuming blowers,etc. need a high level of electric power conversion for their operation. As the power level reaches many megawatts, their oper $\neg$ ations at electrical medium voltage (MV) up to 8 kilovolt $(\mathrm{kV})$ has become advantageous option. However, other issues that are of less importance for low-power drives become issues in medium-voltage operations [10, 11]. For instance, at high power and

Journal homepage: http://iaescore.com/journals/index.php/IJPEDS 
high-voltage levels, technical issues like, bidi $\neg$ rectional power exchange capability or electromagnetic braking in electric drive system is needed when a large quantity of kinetic power is placed in the rotationary bodies. These technical issues can be mitigated by the use of multilevel convert $\neg$ ers due to their capability to produce less distorted currents and small stepped voltage waveforms with a faster switching. Multilevel inverters have applications which include in flexible A.C transmission systems (FACTs). These applications are possible due to multilevel converters' power switches balancing and distributed voltage stress that are shared among the power switches. The multilevel nature signifies producing nearly stepped sinusoidal output AC voltage waveforms with reduced harmonics. Their principles are based on generating small cascade voltage steps for better power quality, thus, operating at a reduced switching frequency with reduced switching losses, small voltage rise change and better electromagnetic compatibility [12].

There are many time domain based control schemes such as direct and in-direct control, power synchronization, and d-q vector control methods. Among these, most commonly employed are direct $p$-q and $\mathrm{d}$-q vector control methods in studying the performance of STATCOMs and VSIs. STATCOM applications for power factor support and stability studies have been employed in [13-17] based on different control schemes. Grid integration and VAR support of MMC inverter has been a challenge [18]. Lawan et al. [19] and Mustapha et al.[20] have employed the direct (p-q) approach to improve the grid PCC power factors using MMC based STATCOM applications. Theoretically, no power loss in an ideal STATCOM system. Resulting in no active power transfer through it. In this state the STATCOM is lossless, its output AC voltage will be in phase with the grid AC voltage. But the d-axis current components control is important considering the facts that during transient operations of the STATCOM, due to charging and discharging of the capacitors, there is always a variation in the active power output of the STATCOMs. In other words there is active power transfer between the grid and the STATCOM. In practical, a small amount of power loss is associated with the process [21]. Specifically in the MMC based Inverters and STATCOMs structural topologies. Each sub modules (SM) has cell capacitor with an active energy stored in it or dc-link voltage sources transferred to them. Without the proper capacitors voltage balancing and energy transfer, the MMC based inverters or STATCOMs will always have some variations in their outputs power, low life time of the cells capacitors due to voltage unbalancing and stress etc.[22-24]. Other variations and /or oscillations can occur due to switching or from non -ideal nature capacitors and buffer inductors [25]. A good tuned PI controller could yield a response with a zero or minimum steady state error within a very small rise time.

But with high settling time and overshoots (i.e. higher oscillation period and a longer response) [2636] and a bit poor dynamics and transient response typical example is in [37]. Another option is the use of Pcontrollers, even though is simpler in implementation, it has a problem of an increased over shoots compared to PI controllers. This increased overshoot could be seen in [37] where it was employed to synchronize the grid voltage and STATCOM output voltage using decoupled current control. The vector control also employs the cascade control principle. In MMC voltage source inverters, the switching frequency is crucial and restricts how quick the VSI can respond to changes from one operating condition to another, therefore the optimal and achievable inner current control band which is also restricted by the employed switching frequency. That is, the controller bandwidth shows how accurate and fast a control signal could change in time, hence how accurate and fast the MMC system response could be [38]. The MMC based inverter based on the cascade control has the current vector control as the inner current control (ICC), and the outer control that comprises the active and reactive power control. On the other hand, the active power control is usually the active power reference or voltage reference based control. The reactive power control is employed in terms of a reference reactive power or reference AC voltage to provide the desired inner current. The advantage of the cascaded schemes is the increased degree of freedom for the control of the system band width due to the controlled time separation of the loops. The controllers of the inner current control are usually used in VSI are proportional-integral-derivative (PID), hysteresis and ramp time current controllers.

The PID and hysteresis are the most common [38]. The hysteresis current control is the fastest control in terms of dynamic response however gives more distortions due to the low order harmonics, variable switching frequency and effect of dead time [37-38]. In the other word, PI-current controllers have maintained switching frequency but that at the expense of a slower response. The PI-controller has its dynamics depending on the dynamic of the system hence has more controlled coupling effect that gives better distortion. But the hysteresis control does not depend on the dynamics of the system plants, hence has high distortions [37-38] compared to their PI-control counterparts. This proposed d,q-compensation algorithm introduces a transient supports based on the concepts of a transient impacts and applied the concepts of the STATCOM parameter variations to produce an algorithms that enhances the control of the STATCOM. The introduced d,q-transient compensator serving only during the transient operations.

Int J Pow Elec \& Dri Syst Vol. 10, No. 4, Dec 2019 : 1781 - 1796 


\section{VECTOR CONTROL FOR MODULAR MULTILEVEL CONVERTER (MMC) INVERTER}

In the vector control scheme depicted in Figure 1, the VSC based MMC system in the three phase voltages and currents are transformed into a direct-quadrature (d-q) rotating frame. From Figure 1 and Figure 2 which presents the vector control scheme, applying Kirchhoff's voltage principles, and based on the Laplace transform, the relationship between the grid $\mathrm{AC}$ voltage $\bar{V}_{\text {fdq }}$ and the MMC system voltage $\bar{V}_{c d q}$ of Figure 1 can be written as follows [39-41]:

$$
s L_{T} \bar{I}_{f d q}=\bar{V}_{c d q}-\bar{V}_{f d q}-R_{T} \bar{I}_{f d q}-j \omega L_{T} \bar{I}_{f d q}
$$

Where:

$R_{T}$ is the effective resistance between the MMC system and the grid

$L_{T}$ is the effective inductance between the MMC system and the grid.

$\bar{V}_{\text {fdq }}$ is the PCC vector voltage.

$\bar{V}_{c d q}$ is the MMC output vector form of the voltage

$\bar{I}_{f d q}$ is the output vector form of the current at the PCC and $\omega$ is the fundamental line frequency.

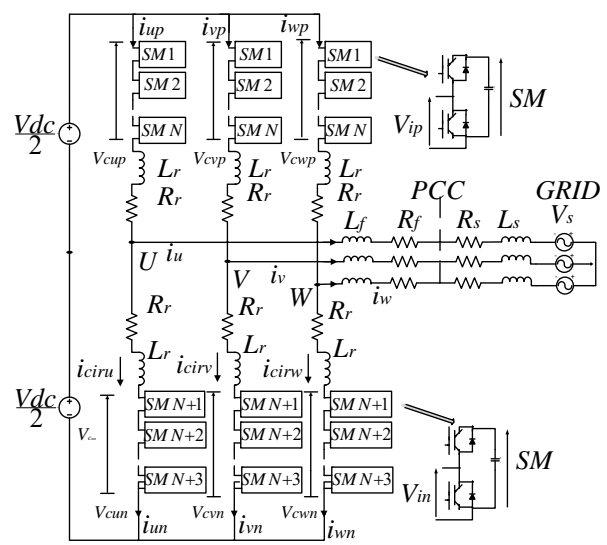

Figure 1 . The three phase internal circuitry of a MMC based STATCOM connected to the three phase grid system.

If a constant power grid system is assumed, then the resultant system could be linear and autonomous. Hence the system is assumed to be an independent variable that is independent of time.This assumption is valid since very small deviations of frequency are expected in a healthy and normal operation of a grid power system. These small variations can only happened as grid is expected to have a constant voltage. From Figure 2 (a), a transfer function for the MMC based VIS q-axis voltage can be written as follows:

$$
\frac{I_{f q}}{-V_{c q}}=\frac{\frac{1}{R_{T}+s L_{T}}}{1+\frac{\left(\omega L_{T}\right)^{2}}{\left(R_{T}+s L_{T}\right)^{2}}}=\frac{R_{T}+s L_{T}}{\left(s+\frac{R_{T}}{L_{T}}\right)^{2}+\omega^{2}}
$$

Where $I_{f q}$ is the output AC current at the point of coupling (PCC) in the q-axis and $V_{c q}$ is the MMC system output voltage in the q-axis.

From (2), the poles of the grid connected MMC system will be roots of the system characteristics equation (denominator of (2): $\left(s+R_{T} / L_{T}\right)^{2}+\omega^{2}$, for $\omega=2 \pi f$, where $f$ is the AC network frequency assumed $50 \mathrm{~Hz}$, these poles of the non -feedback system will be complex in nature, hence the system will be oscillatory. In other words, the grid -connected MMC system will have a bad dynamic performance and poorly damped.

Power compensation for vector-based current control of a modular multilevel ... (A. U. Lawan) 
To solve this control problem of the non-feedback MMC system, the grid-connected MMC current at the PCC (i.e. $I_{f d}$ and $I_{f q}$ ) has to be fed back to the dq-controllers so as to close the current loops. This control improvement is shown in Figure 2 (b). The feedback control loops will improve the system response by shifting the poles of the system open loop transfer function of Figure 2 (a) towards the real axis, thereby pushing the system to have a critically damped response[32]. Assuming the dq-controller to be a simple gain controller (P-controller with $C(s)=K_{P}$ ), then block diagram of Figure 2 (b) can be in a transfer function form with outer feedback loops given by:

$$
\frac{K_{P} \cdot \frac{1}{R_{T}+s L_{T}}}{1+K_{P} \cdot \frac{1}{R_{T}+s L_{T}}}=\frac{K_{P}}{K_{P}+R_{T}+s L_{T}} \approx \frac{1}{1+s L_{T} / K_{P}}
$$

Assuming the inner current controller gain is much more higher than the value of the effective resistance between the MMC system and the grid (i.e. $K_{P} \gg R_{T}$ ), then the equivalent representation of the grid connected MMC system in block diagram will be as shown in figure 3 therefore it is possible to derive a q-axis current transfer function given by (4) and (5). Where $I_{f q}{ }^{*}$ is the grid-connected MMC system q-axis reference current for the inner current control scheme. The same principles applies to their corresponding daxis current.

$$
\frac{I_{f^{q}}}{I_{i^{*}}^{*}}=\frac{\frac{1}{1+s \frac{L_{T}}{K_{p}}}}{1+\left(\frac{\omega L_{T}}{K_{p}}\right)^{2} \frac{1}{\left(1+s \frac{L_{T}}{K_{p}}\right)^{2}}}=\frac{1+s \frac{L_{T}}{K_{p}}}{\left(\frac{\omega L_{T}}{K_{p}}\right)^{2}+\left(1+s \frac{L_{T}}{K_{p}}\right)^{2}}
$$

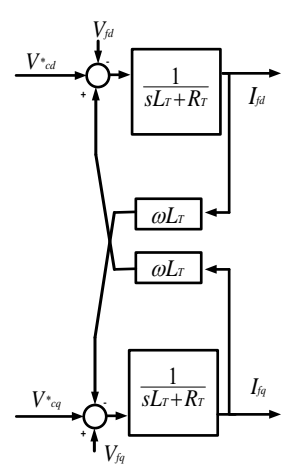

(a)

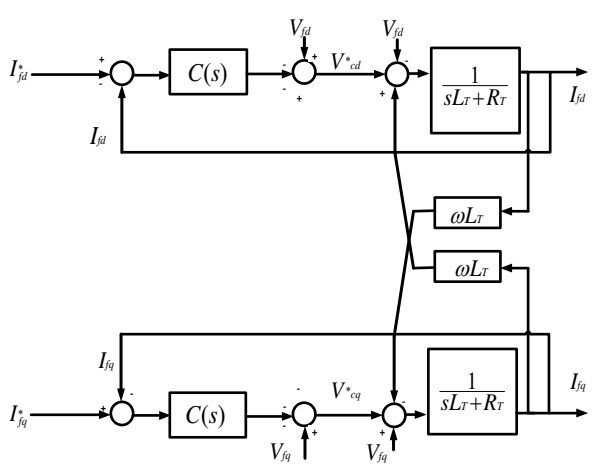

(b)

Figure 2. Block diagram representation of the MMC based VSI in a state space equation (a) without feedback controller (b) with feedback controller

$$
\frac{I_{f_{q}}}{I_{q^{*}}}=\frac{1+s \frac{L_{T}}{K_{0}}}{\left(1+\frac{\omega L_{T}}{K_{0}}+s \frac{L_{T}}{K_{0}}\right)\left(1-\frac{\omega L_{T}}{K_{0}}+s \frac{L_{T}}{K_{0}}\right)} \approx \frac{1}{1+s \frac{L_{T}}{K_{0}}}
$$




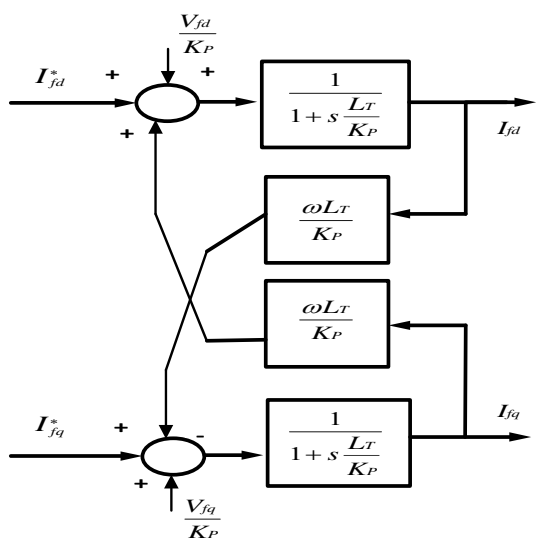

Figure 3. Block diagram representation of the MMC based VSI in a state space equation with decoupled inner current vector controller.

The system obtained from the (5) is a first order system, hence employing a P-controller will improve the system response and helps in the steady state by eliminating the cross coupled interaction between the d-axis and q-axis of the system. The controller will also reduce the effect of the variations in the AC output voltage at the PCC[13]. During the steady state condition (i.e. $S=0$ ), for the block diagram shown in figure 3 , it can give (6) as:

$$
\left.\frac{I_{f q}}{I_{f q}{ }^{*}}=\frac{1}{1+\left(\frac{\omega L_{T}}{K_{P}}\right)^{2}} \approx 1, \frac{I_{f q}}{V_{f q}}=\frac{\frac{1}{K_{P}}}{1+\left(\frac{\omega L_{T}}{K_{P}}\right)^{2}} \approx \frac{1}{K_{P}} \& \frac{I_{f q}}{I_{f d^{*}}}=\frac{\frac{\omega L_{T}}{K_{P}}}{1+\left(\frac{\omega L_{T}}{K_{P}}\right)^{2}} \approx \frac{\omega L_{T}}{K_{P}}\right\}
$$

Where $V_{f q}$ is the AC voltage at the PCC in the q-axis and $I_{f d}{ }^{*}$ is the AC current at the PCC in the d-axis.

Also from (6), the same principle applies to its corresponding d-axis quantities, where their gains can be found by just subtitling the q-axis quantities with the d-axis ones. Analyzing (6), if the term $\omega L_{T} / K_{P} \ll 1$, the MMC inverter output d,q-currents will follow the reference currents (i.e. $I_{f q}=I_{f q}{ }^{*}$ and $I_{f d}=I_{f d}{ }^{*}$ ) exactly, hence the effects of the PCC AC voltage variations will be damped by the controller (i.e. $\left.I_{f q}=V_{f q} / K_{P}\right)$. Also the last term of the (6) implies that the little variations in the d-axis current reference cannot affect the q-axis current in the grid connected MMC.

For a good dynamic performance, if carrier based PWM is employed (i.e. $I_{f q}=\omega L_{T} / K_{P} I_{f d}{ }^{*}$ ), hence the cross coupling effects of the $d$-axis and q-axis are cancelled., the closed -loop band width $\alpha_{c l}$, should not be greater than 5 times the switching frequency $\omega_{s w}$, Also this switching frequency (i.e. $\omega_{s w}$, ) supposed not be lower than half the sampling frequency $\omega_{s}$, i.e. (7)[32]:

$$
\alpha_{c l} \leq \frac{\omega_{s w}}{5} \leq \frac{\omega_{s}}{5(2)}
$$

For instance, if a switching frequency of $2.5 \mathrm{kHz}$ of CSPWM which is $15.70 \mathrm{bkrad} / \mathrm{s}(50 \mathrm{~Hz}=314$ $\mathrm{rad} / \mathrm{s})$ is applied, the highest band width of the system $\alpha_{c l}$, is estimated as $3.14 \mathrm{krad} / \mathrm{s}(500 \mathrm{~Hz})$. Then the rise time, $t_{r}$, which is defined in a first order system as a time the system output goes from 10 to $90 \%$ can be defined as (8)[32]:

$$
t_{r}=\ln (9) / \alpha_{c l}
$$

The STATCOM device is a shunt device hence connected in parallel a with the grid in the power system via a series impedance $Z_{\mathrm{f}}$ which contains a coupling inductor and an assumed negligible series resistance at the PCC[6]. The shunt grid connection is employed using the MMC topology is shown in Figure 1 to derive the proposed control schemes. The basic function of the shunt VAR compensation is to

Power compensation for vector-based current control of a modular multilevel ... (A. U. Lawan) 
give a power factor enhancement or a voltage support by reducing the voltage drop across the uncertain cumulative buffer and coupling impedances $\mathrm{Z}_{\mathrm{t}}$. Hence increases the transmissible power along the grid in a power system. The amount of the required power that will produce the required STATCOM current $i_{c}$ that flows through the coupling impedance $Z_{f}$ is dependent on the difference in voltage between the STATCOM AC output voltage $V_{c}$ and the voltage at the PCC $V_{f}$. If the STATCOM is less in voltage than grid PCC $V_{f}$.

The STATCOM absorbs reactive power from the AC power system. Otherwise it injects reactive power. From Figure 1, the $i_{c q}$ represents the reactive current of the STATCOM while $\boldsymbol{i}_{c d}$ is the active current used in charging and discharging the two DC-link capacitors.

$$
i_{f}=V_{f}-V_{c} \angle \pm \delta \frac{V_{f}-V_{c} \angle \pm \delta}{Z_{f}}
$$

Based on the equation (9) using the diagram representations of Figure 1 the transfer function equations of the STATCOM in d,q- representation is given by:

$$
\left[\begin{array}{l}
V_{c d} \\
V_{c q}
\end{array}\right]=\left[\begin{array}{l}
V_{/ d} \\
V_{i q}
\end{array}\right]+\omega\left(L+\frac{L}{2}\right)\left[\begin{array}{l}
I_{f q} \\
I_{f d}
\end{array}\right]-\left(R+\frac{R}{2}\right)\left[\begin{array}{l}
I_{f q} \\
I_{f d}
\end{array}\right]-\left(\begin{array}{l}
\left.L+\frac{L}{2}\right) \\
)
\end{array}\right) \frac{d}{d t}\left[\begin{array}{l}
I_{f q} \\
I_{f d}
\end{array}\right]
$$

Where $L_{f}$ and $R_{f}$ are the A.C coupling inductance and resistance respectively while $L_{r}$ and $R_{r}$ are MMC inverter buffer inductance and resistance. The cumulative MMC inverter to grid connection inductance and resistance is then defined[22] by (11) when the source impedance is neglected.

$$
Z_{T}=L_{T}+R_{T}=L_{f}+\frac{L_{r}}{2}+R_{f}+\frac{R_{r}}{2}
$$

This implies that there is total impedance $\left(Z_{T}=L_{T}+R_{T}\right)$ between the MMC output and the grid.Integrating $(10)$ between the present sample $(k)$ and the next sample $(k+1)$ the average estimated d,qvariables can be as follows:

$$
\begin{aligned}
& Q_{d}(k, k+1)=V_{f d}(k, k+1)-V_{c d}(k, k+1)+\omega L_{I I f q}(k, k+1)-R_{I I f d} I_{f d}(k) \\
& Q_{q}(k, k+1)=V_{f q}(k, k+1)-V_{c q}(k, k+1)-\omega L_{I I f(k, k+1)} I_{I I} I_{I q}(k)
\end{aligned}
$$

Where the relationship between rates of change of the MMC Inverter output dq currents, the effective inductance in which the current changes and d-q variables respectively is defined in (14) and (15).

$$
\begin{aligned}
\frac{d I_{f d}}{d t} & =\frac{Q_{d}(k, k+1)}{L_{T}} \\
\frac{d I_{f q}}{d t} & =\frac{Q_{q}(k, k+1)}{L_{T}}
\end{aligned}
$$

The d,q-variables $Q_{d}(k, k+1)$ and $Q_{q}(k, k+1)$ from the period of $(\mathrm{k})$ to $(\mathrm{k}+1)$ can be got using PI controllers[26] as:

$$
Q_{, q}(k, k+1)=K_{-i(d, q)}\left(I_{f(d, q)}(k+1)-I_{f(d, q)}(k)\right)+K_{-i(d, q)} \int\left(I_{f(d, q)}(k+1)-I_{f(d, q)}(k)\right) d
$$

These d,q-variables can be used to obtain their corresponding d,q-voltage components at the MMC inverter during the same sample period $((\mathrm{k})$ to $(\mathrm{k}+1))$ as follows:

$$
\begin{aligned}
& V_{c d}(k, k+1)=V_{f d}(k, k+1)+\omega L_{T I} I_{f q}(k, k+1)-R_{T} I_{f d}(k)-Q_{d}(k, k+1) \\
& V_{c q}(k, k+1)=V_{f q}(k, k+1)-\omega L_{T} I_{f q}(k, k+1)-R_{I} I_{f q}(k)-Q_{q}(k, k+1)
\end{aligned}
$$


Where the d, q proportional and integral controllers' gains $K_{P_{-} i(d, q)}$ and $K_{I_{-} i(d, q)}$ which depend on the MMC based STATCOM dynamics during the d,q current sample rates $T_{i(d, q)}$ are respectively given by:

$$
\begin{aligned}
K_{P_{-} i(d, q)} & =\frac{L_{T}}{T_{i(d, q)}}+\frac{R_{f}}{2} \\
K_{I_{-} i(d, q)} & =K_{P_{-} i(d, q)} T_{i(d, q) *} \frac{R_{f}}{L_{T}}
\end{aligned}
$$

These PI controllers fast response makes the STATCOM output d,q current references and the d,qPI variables $Q_{(d, q)}(k, k+1)$ of the next sample period (i.e. $\left.I_{f(d, q)}(k+1)\right)$ meet up with the current sample d,q current references $I_{f(d, q)}^{*}(k)$ and d,q-PI variables $Q_{(d, q)}(k)$ respectively as follows:

$$
\begin{aligned}
& I_{f d}(k+1)=I_{f d}^{*}(k) \\
& I_{f q}(k+1)=I_{f q}^{*}(k) \\
& Q_{(d, q)}(k, k+1)=Q_{(d, q)}(k)
\end{aligned}
$$

For a linear transition between the two sampling periods of (i.e. (kto $k+1)$. (21) and (22) can further be represented in an average form over the time $(k)$ as:

$$
\begin{aligned}
& \frac{1}{2} I_{f d}(k)+\frac{1}{2} I_{f d}^{*}(k)=I_{f d}(k, k+1) \\
& \frac{1}{2} I_{f q}(k)+\frac{1}{2} I_{l q}(k)=I_{f q}(k, k+1)
\end{aligned}
$$

Substituting (21) and (22) into (16) and (17) respectively and using (23) to be represented in a separate d,q form as:

$$
\begin{aligned}
& Q_{d}(k)=K_{p_{-} i(d)}\left(I_{f d}^{*}(k)-I_{f d}(k)\right)+K_{\__{-} i(d)} \int\left(I_{f d}^{*}(k)-I_{f d}(k)\right) d t \\
& Q_{q}(k)=K_{P_{-} i(q)}\left(I_{f q}^{*}(k)-I_{f q}(k)\right)+K_{\left.\Sigma_{-} i(q)\right)} \int\left(I_{f q}^{*}(k)-I_{f_{q}(k)}(k) d t\right.
\end{aligned}
$$

Due to the action of the PI variables represented in the (24) and (25). The grid d,q voltages and the MMC based STATCOM output d,q voltages are assumed to be the :

$$
\begin{aligned}
& V_{f(d, q)}(k, k+1)=V_{f(d, q)}(k) \\
& V_{c(d, q)}(k, k+1)=V^{*}{ }_{c(d, q)}(k)
\end{aligned}
$$

Putting (21)-(27) into (17) and (18) gives the d,q voltage components at the MMC STATCOM inverter, which serve as the d,q voltage references employed using the PI controllers. These voltage references are defined by:

$$
\begin{aligned}
& V_{c d}^{*}(k)=-K_{P_{-} i(d)}\left(I_{f d}^{*}(k)-I_{f d}(k)\right)-K_{I_{-} i(d)}\left(I_{f d}^{*}(k)-I_{f d}(k)\right) d t+V_{f d}(k)+\frac{\omega L_{T}}{2}\left(I_{f q}(k)+I_{f q}^{*}(k)\right)-R_{I I f d}(k)(30) \\
& V_{c q}^{*}(k)=-K_{P_{-} i(q)}\left(I_{f q}^{*}(k)-I_{f q}(k)\right)-K_{I_{-} i(q)}\left(I_{f q}^{*}(k)-I_{f q}(k)\right) d t+V_{f q}(k)-\frac{\omega L_{T}}{2}\left(I_{f d}^{*}(k)+I_{f d}(k)\right)-R_{T} I_{f q}(k)(31)
\end{aligned}
$$

Equations (30) and (31) which represent the d,q voltage references to the PWM control modulator can be further represented in terms of the estimated d,q variables ( i.e. $Q_{d}(k) Q_{q}(k)$ ) as part of the feed forward terms[26] as: 


$$
\begin{gathered}
V_{c d}^{*}(k)=-Q_{d d}(k)+V_{f d}(k)+\frac{\omega L_{T}}{2}\left(I_{f q}(k)+I_{f q}^{*}(k)\right)-R_{T} I_{f d}(k) \\
V_{c q}^{*}(k)=-Q_{(q)}+V_{f q}(k)-\frac{\omega L_{T}}{2}\left(I_{f d}^{*}(k)+I_{f d}(k)\right)-R_{T} I_{f q}(k)
\end{gathered}
$$

Where $Q_{d}(k)$ and $Q_{q}(k)$ ) defined previously in (26) and (27) respectively represent the settled dq variables (i.e. $Q_{d}$ and $Q_{q}$ ) given in (34) and (35), obtained as outputs of the d,q-PI controllers of a voltage control dynamic model based on the decoupled inner current control of the STATCOM grid connected system[26], shown in Figure 4.

$$
\begin{aligned}
& Q_{d}=K_{P_{-} i(d)}\left(I_{f d}^{*}-I_{f d}\right)+K_{I_{-} i(d)} \int\left(I_{f d}^{*}-I_{f d}\right) d t \\
& Q_{q}=K_{P_{-} i(q)}\left(I_{f q}^{*}-I_{f q}\right)+K_{I_{-} i(q)} \int\left(I_{f q}^{*}-I_{f q}\right) d t
\end{aligned}
$$

The reference MMC based STATCOM modulation index $m$ and phase shift angle $\delta$ that produce the inverter three phase AC currents (i.e. $\left.i_{k}=I \sin \left(\omega_{o} t\right)\right)$ and voltages $\left(V_{c k}=V \sin \left(\omega_{o} t+\theta\right)\right)$ has the subscript (i.e. ${ }_{k}$ ) representing phase number, and $\theta$ is the phase shift between the output current and voltage in AC form given by (36) and (37) respectively as follows:

$$
\begin{aligned}
& m=\sqrt{V_{c d}^{* 2}+V_{c q}^{* 2}} \\
& \delta=\tan ^{-1} \frac{V_{c q}^{*}}{V_{c d}^{*}}
\end{aligned}
$$

For the MMC internal control, it employed the common control concepts used in[27][28][24] that utilized the concepts of Carrier shifted pulse width modulation schemes ( CSPWM ) [6][29][30] [13][12]. Applying the Kirchhoff's theory, the AC voltage in the arm as an output can be derived as follows:

$$
V_{c k o}=\frac{1}{2}\left(V_{c k n}-V_{c k p}\right)-\frac{1}{2}\left(L_{r} \frac{d i_{k}}{d t}+R_{r} i_{k}\right)(38), 2\left(L_{r} \frac{d i_{\text {cirk }}}{d t}+R_{r i c i k k}\right)=V_{d c}-\left(V_{c k n}+V_{c k p}\right)(39
$$

Where $i_{\text {cirk }}$ is the circulating current and $V_{d c}$ is the cumulative dc -link voltage across the arms. $L_{r}$ is the buffer arm inductance of each arm. $R_{r}$ is the series resistance associated with each buffer inductance that is usually assumed negligible[27]. $L_{f}$ and $R_{f}$ are the AC coupling inductance and its corresponding series resistance respectively. If the MMC is connected to grid, then there will be a source impedance $R$ s and $L_{s}$ (i.e. the AC source inductance and its corresponding AC source series resistance respectively). The mathematical relationship between the MMC output current of each phase, the arm upper and lower currents, the circulating current and output voltage could be as:

$$
\begin{array}{r}
i_{k}=i_{k p}-i_{k n} \\
i_{c i r k}=\frac{1}{2}\left(i_{k p}+i_{k n}\right) \\
V_{c k}=\frac{1}{2}\left(V_{c k n}-V_{c k p}\right)
\end{array}
$$

Based on (38) - (39), the regulation of the circulating current $i_{\text {cirk }}$ and control of the output voltage $V_{c k}$ could be achieved by controlling the upper and lower currents and upper and lower voltages. In other word, to achieve the desired output voltage and maintain the balance between the entire DC voltage and each phase leg output voltage, the output voltages can be defined as:

Int J Pow Elec \& Dri Syst Vol. 10, No. 4, Dec 2019 : 1781 - 1796 


$$
\begin{aligned}
& V_{c k p}=\frac{1}{2} V_{d c}-V_{c k} \\
& V_{c k n}=\frac{1}{2} V_{d c}+V_{c k}
\end{aligned}
$$

Where $V_{c k}$ is the MMC system output voltage of the corresponding phase defined as:

$$
V_{c k}=\frac{1}{2} V_{\mathrm{dc}^{*}} M \sin \left(\omega_{o} t-\theta_{k}\right)
$$

\section{THE PROPOSED COMPENSATING DQ -POWER ALGORITHMS ( $Q_{\text {dcom }}$ AND $\left.Q_{q c o m}\right)$ FOR MMC BASED STATCOM DECOUPLED CURRENT CONTROL.}

Many attempts to enhance grid voltage or power factor were considered using external reactive currents such as in [6],[31]. These external compensating reactive currents were made from the q-axis components only and introduced as a means of compensating the line load reactive current references. But the d-axis component compensation generation was not considered. Given by (34) and (35) and figure 1, based on the d,q- frame nature of d,q- inner current vector control there will always be the d-axis and q-axis in its implementation. Also considering the facts that the PI controllers are implemented in d,q independent form to control the active and reactive power independently for getting a decoupled dynamic response[22], this work introduced another components (i.e. d-axis active vector compensation components) to compensate for the d-axis segment of the d,q-variable (i.e. $Q_{d}$ and $Q_{q}$ ), plus the q-axis reactive vector compensation components) to compensate for the q-axis segment of the d,q-variable.

The variables (i.e. $Q_{d}$ and $Q_{q}$ ) were obtained and applied for the corresponding d,q-PI controllers of the d,q-inner current controllers. This external compensation is important considering the facts that all VSI inverters have either a dc link capacitor(s) or source of dc-link voltages that need an active power control which are mostly carried out by either from set of a reference active power or by the use of a reference voltage to control the dc link voltage as a means of controlling the active power. In other word, the variation of the MMC based STATCOM active power within its cells is also tackled using the d-axis components compensation in this work, considering the widened causes and forms of STATCOM variations. On the other hand, given by (40) and (14) and Figure 8. It can be seen that the extraction of the q-axis current components (i.e. load reactive current $\left.I_{l_{q}}(k)\right)$ is required in maintaining the grid voltage or correct the power factor of the power system at the PCC. This is used as the reactive current reference $I_{f q}^{*}(k)$ in order to effectively control the variations. The proposed power algorithm ( $Q_{d c o m}$ and $Q_{q c o m}$ ) was derived to basically to produce an opposite d,q- power commands to the d,q- PI controller's output variables ( $Q_{d}$ and $\left.Q_{q}\right)$ in response to the STATCOM active and reactive currents variation during the steady state operation. Assuming that in the STATCOM non-ideal operation, the output current has not only the reactive current components $I_{f q}$ but also has a very small active current components[5] in it its operations $I_{f d}$ that has some variations.

This small active current variation was considered due to a very small real power exchange assuming a steady state operation of the STATCOM. Therefore, during the transients (i.e. Figure 5), the active current $I_{f d}$ flows in order to maintain the capacitors voltages during charging and discharging. Hence, a small internal active power loss is associated across the resistance $R_{T}$. Also assuming the power loss due to the voltage drop $V_{L}$ across the cumulative inductance $L_{T}$ considering the STATCOM operation in quadrant I and quadrant II regions of Figure 5. In these two regions, the STATCOM injects positive reactive power to the grid and absorb a very negligible amount of active power for the dc voltage maintenance respectively. Then the STATCOM can attain a steady state, when compensated and it's the d-axis and q-axis current components $I_{f d}$ and $I_{f q}$ in (34) and (35) respectively will be driven to the desired d-axis and q-axis current components $I_{i d}^{*}$ and $I_{f_{q}}^{*}$. After the compensation, that is in the steady state, the rate of change of the STATCOM currents $I_{f d}$ and $I_{f q}$ will be zero as:

$$
\frac{d I_{f(d, q)}}{d t}=0
$$


Assuming also the cumulative effective resistance $R_{T}$ to be negligible during the steady state, and given by:

$$
R_{f}+\frac{R_{r}}{2}=R_{T}=0
$$

Then current components $I_{f d}^{*}$ and $I_{f q}^{*}$ would have their resultant line current value $I_{f}$ in quadrature with the available AC voltage at the grid PCC as shown in figure 1. From the Figure 1 it can be seen that the at the steady state condition, the grid AC voltage $V_{d}$ will also be in phase with STATCOM output AC voltage $V_{c}$ and the controller at this state, will generate the desired compensating voltage commands with their magnitudes $V_{f d}^{*}$ and $V_{f q}^{*}$ that can be as:

$$
\begin{aligned}
& V_{c d}^{*}=V_{f d}+\omega L_{T} I_{f q}^{*} \\
& V_{c q}^{*}=\omega L_{T} I_{f d}^{*}
\end{aligned}
$$

Considering that in decoupled current control, the voltage vector is always aligned with the d-axis, then grid q-axis voltage vector $V_{f q}$ can be ignored. Hence $V_{f q}=0$.On the other hand, the grid d-axis voltage vector $V_{f q}$ is defined in interns of resultant STATCOM d-axis voltage command $V_{c d}^{*}$ in (48) based on the opposing voltage drop signal (i.e. $\omega L_{T} I_{f q}^{*}$ ), $V_{c q}^{*}$ is the resultant STATCOM q-axis that equals the opposing voltage drop signal $\omega L_{T} I_{f d}^{*}$.

If from (48 and 49) the corresponding desired d-axis and q-axis STATCOM currents can be defined as:

$$
\begin{gathered}
I_{f d}^{*} \frac{V_{c q}^{*}}{\omega L_{T}} \\
I_{f q}^{*} \frac{-\left(V_{c d}^{*}-V_{f d}\right)}{\omega L_{T}}
\end{gathered}
$$

Where the cumulative interfacing inductance $L_{T}$ is given by:

$$
L_{T}=L_{f}+\frac{L_{r}}{2}
$$

Their compensating steady-state active and reactive power variables $\left(Q_{\text {dcom }}\right.$ and $\left.Q_{q c o m}\right)$ at the filter $\mathrm{PCC}$ bus is as:

$$
\begin{aligned}
& Q_{d c o m}=\frac{3}{2} V_{f d} I_{f d}^{*}=\frac{3}{2} \frac{V_{c q}^{*} V_{f q}}{\omega L_{T}}=V I_{f d}^{*} \\
& Q_{q c o m}=-\frac{3}{2} V_{f d} I_{f q}^{*}=\frac{3}{2} \frac{V_{c d}^{*} V_{f d}}{\omega L_{T}}-\frac{3}{2} \frac{V_{f d}^{2}}{\omega L_{T}}=V I_{f d}^{*}
\end{aligned}
$$

From (9) supported by figure 4, can be seen that the cumulative inductance $L_{T}$ is not only employed for filtering purpose and coupling but is also inevitable for creating a very small phase shift $\delta$ that will enable the active power exchange during the capacitors transients. On the other hand, from the (9), it can be seen that the voltage difference between the d-axis grid voltage and the d-axis STATCOM voltage represents the voltage difference $\left(V_{c d}^{*}-V_{f d}\right)$ over the cumulative inductance $L_{T}$. Rearranging (54) as shown in $(55)$ :

$$
Q_{q c o m}+\frac{3}{2} \frac{V_{f d}^{2}}{\omega L_{T}}=\frac{3}{2} \frac{V_{c d}^{*} V_{f d}}{\omega L_{T}}
$$

Then the STATCOM resultant output voltage $V_{c}^{*}$ is given as

Int J Pow Elec \& Dri Syst Vol. 10, No. 4, Dec 2019 : 1781 - 1796 


$$
V_{c}^{* 2}=V_{c d}^{* 2}+V_{c q}^{* 2}
$$

Also squaring the (53) and (54) and adding them, as an equation given by (57). (57) will represent a circle equation that presents the MMC inverter active and reactive power capability curve shown in figure 6.

$$
Q_{d c o m}^{2}+\left(Q_{q c o m}+\frac{3}{2} \frac{V_{f d}^{2}}{\omega L_{T}}\right)^{2}=\left(\frac{3}{2} \frac{V_{c} V_{f d}}{\omega L_{T}}\right)^{2}
$$

Figure 6 depicts the regions below and above the active power axis, also shows the under excitation and over citation regions, where the converter injects and absorbs reactive power from and to grid. Therefore for a successful control of an MMC Inverter, the net reactive power $Q_{q}$ available for manipulation at the PCC filter bus should be greater than the $Q_{q}$ absorbed by the cumulative filter inductance. Based on (57), the cumulative filter inductance $L_{T}$ must be selected assuming the active and reactive power MMC inverter capability at a maximum active and reactive power values. Therefore, (58) can be rewritten as:

$$
\omega L_{T}^{2} Q_{d \max }^{2}+\left(L_{T} Q_{q \max }+\frac{3}{2} V_{f d}^{2}\right)^{2}-\left(\frac{3}{2} V_{c} V_{f d}\right)^{2}=0
$$

For an ideal reactive power STATCOM applications in a steady state, the active power $Q_{d}$ in (58) can be considered negligible ( $Q_{d}=\simeq 0$ ), therefore (58) can be reduced to:

$$
Q_{q \max }=\frac{3}{2} \frac{V_{f d}}{\omega L_{T}}\left(V_{c}-V_{f d}\right)
$$

However, due to the MMC inverter nonlinearity in its typical control operations[13-40], there is always, a small voltage difference between the STATCOM output voltage $V_{c}$ and the grid voltage $V_{f}$ ( which is assumed to be constant). In other word, the voltage difference $V_{l}$ is not exactly equal to zero even during the steady state operation. . To enhance the control in pushing the load line current signals ( $I_{f d}$ and $I_{f q}$ ) in tracking their desired values $I_{f d}^{*}$ and $I_{f q}^{*}$, the proposed d,q algorithm is employed to detects the voltage difference which are proportional to the externally provided proposed d,q-power algorithm variables as a feedforward terms to the decoupling inner current control scheme. These provided d,q power variables are added to the outputs of the d,q-PI controllers in a decoupled form compensating the variables to the STATCOM reactive and active power variations. Note: the active power variation is negligible compared to the reactive power) variations. From (53 and 54), the proposed d,q-power algorithms will die when the STATCOM resultant output voltage $V_{c}^{*}$ has reached its steady state value of unity.

This compensated state would be reached as soon as the dq-power variables have pushed the STATCOM controlled system attained the maximum values available for control at the PCC bus. This coincides with the points in figure 5 where the maximum power is achieved ( $\mathrm{PF}$ is unity based on the load reactive current) after overcoming the required minimum values for the power absorption in the interfacing reactors. Figure 7 shows the block diagram of the proposed compensating dq power variables for the MMC based STATCOM decoupled inner current control (MMC external control). Finally, the compensating d,q power variables $\left(Q_{\text {dcom }}\right.$ and $\left.Q_{q c o m}\right)$ are then added to the d,q-PI controller terms $\left(Q_{d}\right.$ and $\left.Q_{q}\right)$ in $(32$ and 33$)$ respectively to form the final d,q-voltage component references $\left(V^{*}{ }_{c d}(k)\right.$ and $\left.V^{*}{ }_{c q}(k)\right)$ respectively of the decoupled current vector control for the modulation as follows:

$$
\begin{gathered}
V^{*}{ }_{c d}(k)=-Q_{d}(k)+Q_{d c o m}(k)+V_{f d}(k)+\frac{\omega L_{T}}{2}\left(I_{f q}(k)+I_{f q}^{*}(k)\right)-R_{T} I_{f d}(k) \\
V^{*}{ }_{c q}(k)=-Q_{q}(k)+Q_{q c o m}(k)+V_{f q}(k)-\frac{\omega L_{T}}{2}\left(I_{f d}^{*}(k)+I_{f d}(k)\right)-R_{T} I_{f q}(k)
\end{gathered}
$$

This transient action would help in tackling the natural poor dynamics of d, q-PI controllers that produced d,q-PI variables therefore, enhancing the overall control system response of the MMC based STATCOM. In other words, the integral controller of the inner current d, q-PI controllers accepts the efforts provided by the transient compensator.

Power compensation for vector-based current control of a modular multilevel ... (A. U. Lawan) 
Once the MMC based STATCOM current is driven into state of a desired current, the steady state inner current controller would produce a PCC voltage command consistent with the MMC based STATCOM line current,

Therefore depressing the contribution effort provided by the external transient state compensator. Sine well designed PI controller's exhibit the properties of improved rise time and also has the integral function to eliminate the steady state error. They have been chosen and employed in this paper for achieving fast and better control of the STACOM reactive and compensated for an improved transient responses.

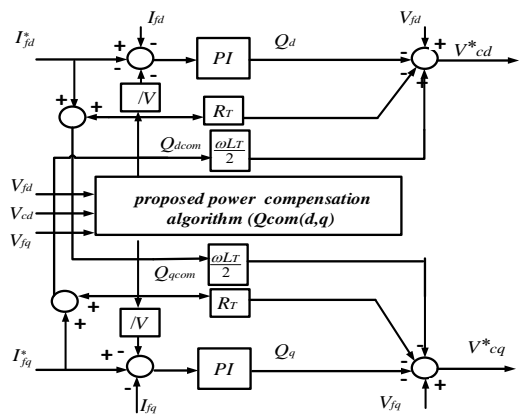

Figure 4. The proposed d,q-power algorithm( $Q_{d c o m}$ and $\left.Q_{q c o m}\right)$

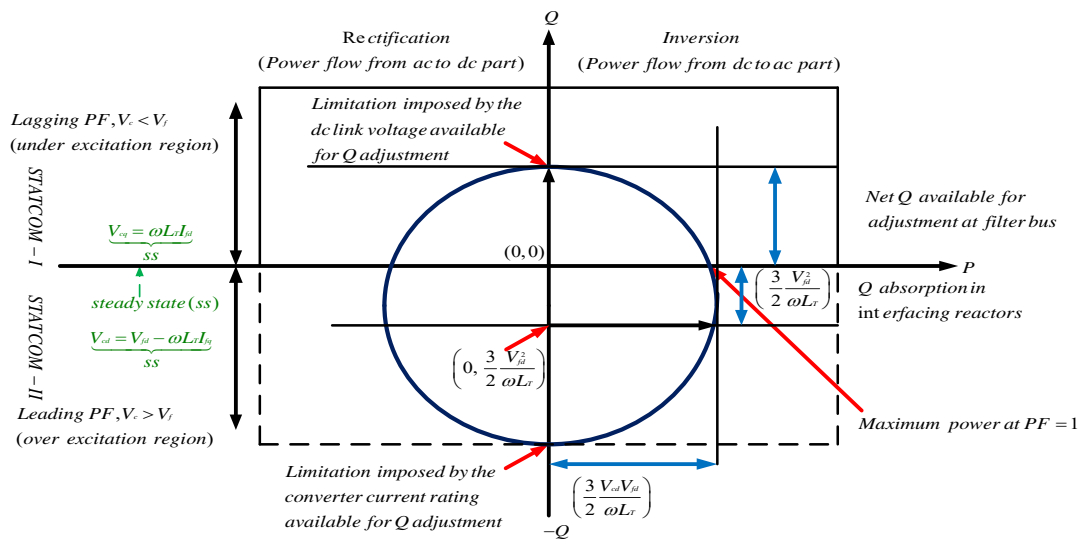

Figure 5. Theoretical capability curve of the MMC based inverters for STATCOM applications manipulations

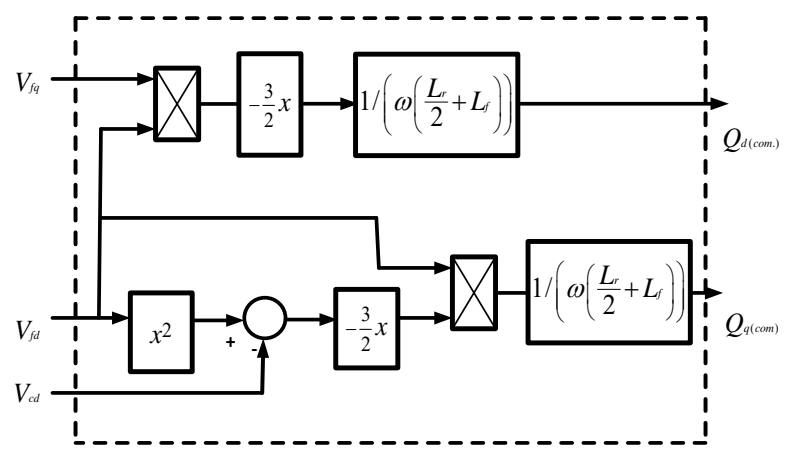

Figure 6. Block diagram of the proposed compensating dq power variables for the MMC based STATCOM decoupled inner current control (MMC external control) for reactive power manipulations 


\section{RESULT AND DISCUSION}

The STATCOM is built based on the MMC topology for a five level operations using a Simulink model and the grid emulator is developed using the parameters shown in Table 1. The control gains for the MMC internal control were also summarized in Table 2 . The preliminary setup of the experimental system is underway, built based on the same 5-level phase shifted PWM and balancing technique.

Table 1. Control system parameters of the grid connected mmc based

\begin{tabular}{lll}
\hline Symbol & \multicolumn{1}{c}{ Quantity } & \multicolumn{1}{c}{ Value } \\
\hline$f$ & Fundamental frequency & $50 \mathrm{~Hz}$ \\
$f_{s w}$ & Switching frequency & $4 \mathrm{kHz}$ \\
$V_{f}$ & Grid voltage & $50 \mathrm{~V}_{\text {rms }}$ \\
$R_{s}$ & Grid resistor & $0.500 \mathrm{~m} \Omega$ \\
$L_{s}$ & Grid inductor & $0.120 \mathrm{mH}$ \\
$R_{f}$ & AC coupling resistor & $0.100 \mathrm{~m} \Omega$ \\
$L_{f}$ & AC coupling inductor & $2 \mathrm{mH}$ \\
$R_{r}$ & MMC buffer resistor & $0.400 \mathrm{~m} \Omega$ \\
$L_{r}$ & MMC buffer inductor & $2 \mathrm{mH}$ \\
$C_{e}$ & Effective capacitor(s) & $800 \mathrm{uF}$ \\
$V_{d c}$ & DC link voltage & $110 \mathrm{~V}$ \\
$R L$ & Active -inductive Load (kw/Kvar) & $500 / 500$ \\
$R C$ & Active-capacitive Load (kw/Kvar) & $500 / 500$ \\
$K_{P \_d, q}$ & d-q-axis proportional current gain & 2800 \\
$K_{I \_d, q}$ & d-q-axis Integral inner current gain & 300 \\
\hline
\end{tabular}

Table 2. Control system parameters of the capacitor voltage balancing for mmc based statcom system simulation

\begin{tabular}{lll}
\hline Symbol & \multicolumn{1}{c}{ Quantity } & Value \\
\hline$K 1$ & Proportional inner dc current gain & 0.16 \\
$K 2$ & Integral inner dc current gain & 49 \\
$K 3$ & Proportional outer dc capacitor & 7.5 \\
$K 4$ & voltage gain & 375 \\
$K 5$ & Integral outer dc capacitor voltage & 0.5 \\
K6 & gain & 0.5 \\
& Proportional arm de voltage gain & \\
& Proportional individual cap. dc \\
& voltage gain & \\
\hline
\end{tabular}

\section{SIMULATION RESULTS}

The controllers have a time delay of 200milliseconds and, each MMC cell employed the ideal IGBTs that have no dead time. Since each MMC cell has a carrier frequency of $4 \mathrm{kHz}$. This means the total switching frequency of the MMC system is $16 \mathrm{kHz}(4 \mathrm{kHz}$ times 4$)$. In order to authenticate the proposed control and its theoretical analysis validity, two operating conditions of STATCOM (i.e. capacitive and inductive mode) were considered in these simulations. The active and reactive loads shown in Figure 7 and Figure 8 respectively have better dynamic responses that reached stability at almost 8 cycles before the step change with better responses to the change of the load at $0.4 \mathrm{~s}$.

Figure 8 depicts the load reactive power transition from capacitive to inductive to state of both the conventional and The proposed scheme has reached its steady value at about 0.01 seconds from the start of the simulation, but in the conventional scheme, the response has fluctuated before settling at time 0.2 seconds which equivalent to 10 cycles based on the $50 \mathrm{~Hz}$ used, these responses have shown the superiority of the proposed scheme. Figure 9 shows the load power factor response during the transition from capacitive to inductive state of the MMC based STATCOM operations But the overshoot in the Figure 9 is dominated by the green colour, meaning the overshoot of the conventional is more than that of the proposed scheme at the transition state. The power factor was chosen to be 0.7 for the capacitive and inductive load (500VAR). Figure 11 shows the MMC based STATCOM AC output voltage fast Fourier transform (FFT) analysis for the voltage harmonics using the proposed decoupled inner current control. It can be seen that the proposed control based output voltage has FFT of $1.50 \%$ ( Figure 11). While its counterpart in the conventional has $2.07 \%$ (Figure 12). Also, from the graphical results, both have shown that at fundamental frequency there is significant level of harmonics magnitude ( i.e. of about more than one (1) magnitude total harmonic distortion (THD)) and almost the same level at second harmonic both with reducing magnitudes, but in the proposed control scheme, there is better level of harmonics. though both have complied with IEEE standard (i.e. less than $5 \%$ THD).

Figure 12 depicts the FFT analysis of the controlled capacitors voltage harmonics during the STATCOM and balancing control operations using the proposed decoupled inner current control of the MMC based STATCOM with grid. The total harmonics level in Figure 12 has to be $44.98 \%$ THD, the controlled capacitors voltage has shown an overshoot in the response of about 60vdc but settled at about 0.14 seconds which is shorter time.

Figure 13 has shown the FFT analysis of the controlled capacitors voltage harmonics during the STATCOM and balancing control operations based on the conventional scheme with about $77.77 \%$ THD (1.7 times 44.98\%) which has almost doubled that of the proposed scheme. Also the proposed response has settled at about 0.14 seconds which is faster than the conventional response with about 0.04 seconds $(2-50 \mathrm{~Hz}$ cycles).From the figures (Figure 12 and 13), it can be seen that the forth order harmonic and above (firth, six, seven etc.), both the even and odd values are almost zero in both control schemes (i.e. conventional and proposed scheme But for the proposed method, is only the fundamental and second order harmonics are close

Power compensation for vector-based current control of a modular multilevel ... (A. U. Lawan) 
to 100 mag. (\%of fundamental). In case of the conventional control scheme, the harmonics' presence has reached to the third order level with a value close to also $100 \mathrm{mag}$. (75\%of fundamental)

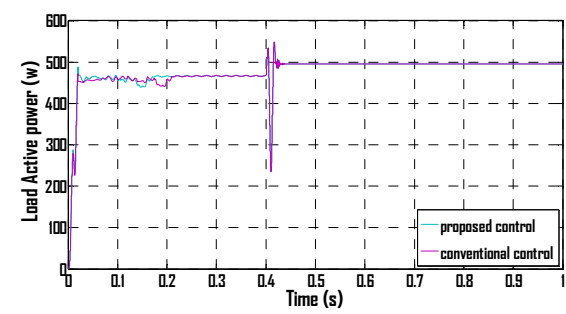

Figure 7. Load active power transition from inductive to capacitive state

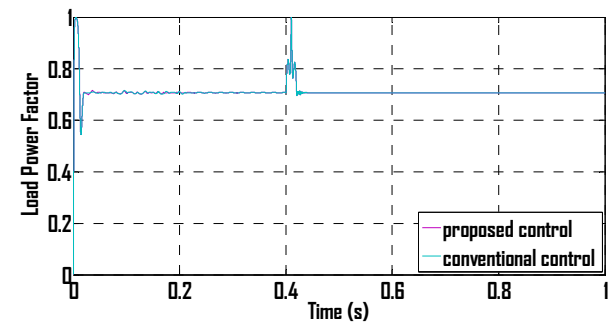

Figure 9. Load power factor during the transition from capacitive to inductive state

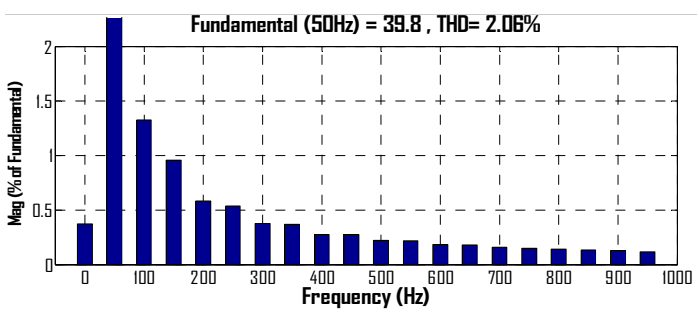

Figure 11. STATCOM AC output voltage FFT analysis for the voltage harmonics using the conventional decoupled inner current control

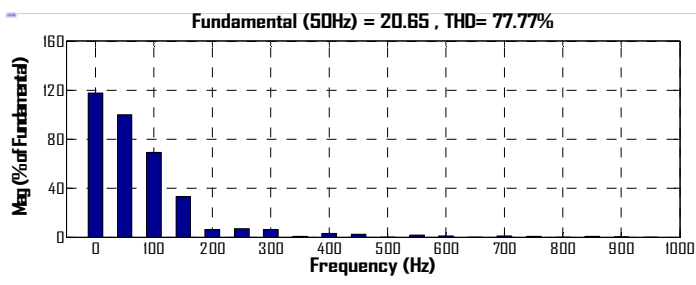

Figure 13. FFT analysis of the controlled capacitors voltage harmonics using the conventional decoupled current control of the gridMMC based STATCOM

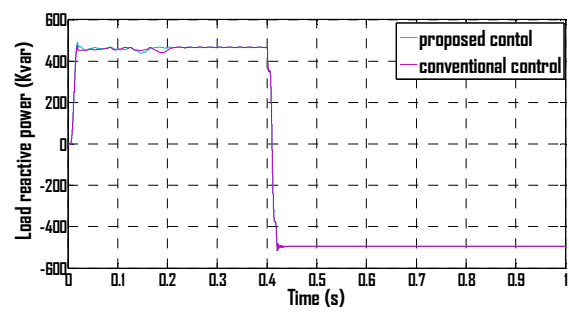

Figure 8. Load reactive power transition from capacitive to inductive state

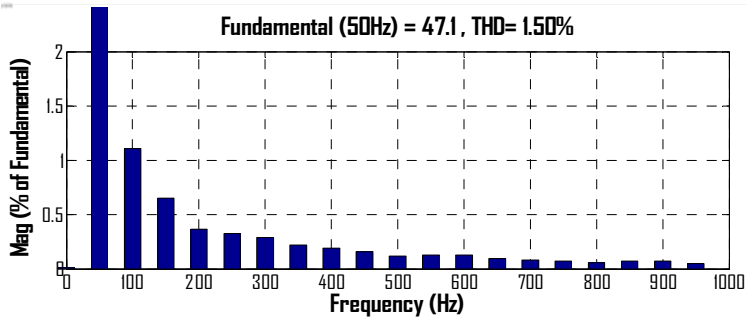

Figure 10. MMC based STATCOM AC output voltage FFT analysis for the voltage harmonics using the proposed decoupled control

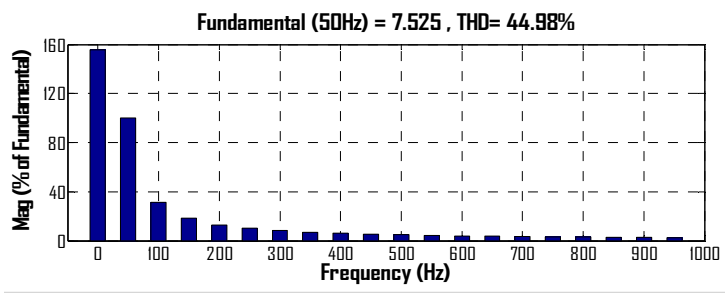

Figure 12. FFT analysis of the controlled capacitors voltage harmonics using the proposed decoupled inner current control of the grid- MMC based STATCOM

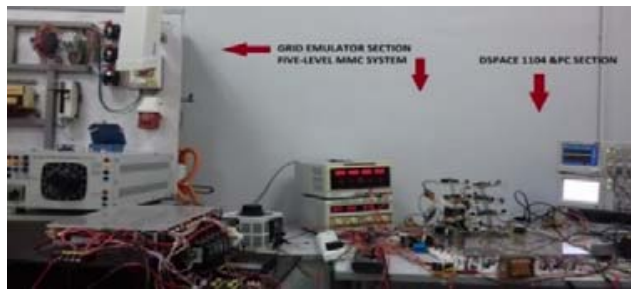

Figure 14. Preliminary Experimental setup of the small proto type Grid-connected Five-Level MMC based STATCOM 


\section{CONCLUSION}

This paper has investigated simplicity of carrier-based PWM technique in the STATCOM applications, afterwards, an enhancement on the performance of vector control based MMC is exploited. This has been achieved without the use of additional equipment or use of low switching complicated technique such the SHE. The proposed transient action introduced has helped in tackling the setback of dynamics of PI controllers and the STATCOM non-idealities; thus, it has enhanced the overall control system response of the MMC based STATCOM system. Finally, simulation are presented. In other words, the integral controllers of the inner current PI controllers have accepted the efforts provided by the transient compensators. This development can be used to achieve the practical realization of STATCOM with reduced variations.

\section{REFERENCES}

[1] L. K. Haw, M. Dahidah, and N. Mariun, "Cascaded multilevel inverter based STATCOM with power factor correction feature," 2011 IEEE Conf. Sustain. Util. Dev. Eng. Technol. STUDENT, no. October, pp. 1-7, 2011.

[2] P. Rao, M. L. Crow, and Z. Yang, "STATCOM control for power system voltage control applications," IEEE Trans. Power Deliv., vol. 15, no. 4, pp. 1311-1317, 2000.

[3] K. Ilango, A. Bhargav, A. Trivikram, P. S. Kavya, G. Mounika, and M. G. Nair, "Power Quality Improvement using STATCOM with Renewable Energy Sources," Power Electron. (IICPE), 2012 IEEE 5th India Int. Conf., p. $1-6,2012$.

[4] A.U. Lawan, "State Feedback Approaches for Designing A Statcom Supplementary Controller for Oscillations Damping," Int. J. Eng. Sci., vol. 3, no. 7, pp. 27-37, 2014.

[5] N. Magaji, A. U. Lawan, A. D. O. Dan-isa, and M. W. Mustafa, "Design A STATCOM supplementary Controller for Stability Studies using various state feedback algorithm," Recent Res. Circuits Syst., pp. 38-43, 2012.

[6] L. K. Haw, M. S. A. Dahidah, S. Member, H. A. F. Almurib, and S. Member, "A New Reactive Current Reference Algorithmfor the STATCOM System Based on Cascaded Multilevel Inverters," IEEE Trans. POWER Electron., vol. 30, no. 7, pp. 3577-3588, 2015.

[7] J. M. Lozano, J. M. Ramirez, and R. E. Correa, "A novel Dynamic Voltage Restorer based on matrix converters," Proc. - Int. Symp. Mod. Electr. Power Syst. MEPS’10, no. 1145, pp. 1-7, 2010.

[8] "Performance Analysis of Interline Unified Power Flowcontroller for parallel transmission lines," Electr. Comput. Commun. Technol. (ICECCT), 2015 IEEE Int. Conf., pp. 1-8, 2015.

[9] A.U. Lawan, N. Magaji, and H. Musa, "A STATCOM Controller for Small Signal Stability using Polynomial Algorithms in a Horizontal Axis Wind Farm Power System," 2013 IEEE Energytech USA, pp. 1-5, 2013.

[10] M. Hagiwara, K. Nishimura, and H. Akagi, "A modular multilevel PWM inverter for medium-voltage motor drives," 2009 IEEE Energy Convers. Congr. Expo. ECCE 2009, vol. 1, no. c, pp. 2557-2564, 2009.

[11] G. P. Adam, K. H. Ahmed, S. J. Finney, and B. W. Williams, "Modular multilevel converter for medium-voltage applications," 2011 IEEE Int. Electr. Mach. Drives Conf. IEMDC 2011, pp. 1013-1018, 2011.

[12] S. Debnath, J. Qin, B. Bahrani, M. Saeedifard, and P. Barbosa, "Operation, Control, and Applications of the Modular Multilevel Converter: A Review," IEEE Trans. Power Electron., vol. PP, no. 99, pp. 1-1, 2014.

[13] M. a. Perez, S. Bernet, J. Rodriguez, S. Kouro, and R. Lizana, "Circuit Topologies, Modelling, Control Schemes and Applications of Modular Multilevel Converters," IEEE Trans. Power Electron., vol. PP, no. 99, pp. 1-1, 2014.

[14] J. Rodríguez, S. Bernet, B. Wu, J. O. Pontt, and S. Kouro, "Multilevel voltage-source-converter topologies for industrial medium-voltage drives," IEEE Trans. Ind. Electron., vol. 54, no. 6, pp. 2930-2945, 2007.

[15] F. Khoucha, A. Ales, A. Khoudiri, K. Marouani, M. E. H. Benbouzid, and A. Kheloui, "A 7-level single DC source cascaded H-bridge multilevel inverters control using hybrid modulation," 19th Int. Conf. Electr. Mach. ICEM 2010, no. 1, 2010

[16] S. R. Pulikanti and V. G. Agelidis, "Control of neutral point and flying capacitor voltages in five-level SHEPWM controlled ANPC converter,” 2009 4th IEEE Conf. Ind. Electron. Appl. ICIEA 2009, pp. 172-177, 2009.

[17] G. Gateau, T. A. Meynard, L. Delmas, and H. Foch, "Stacked multicell converter (SMC): Topology and control,” EPE J. (European Power Electron. Drives Journal), vol. 12, no. 2, pp. 14-18, 2002.

[18] P. Sotoodeh and R. D. Miller, "A single-phase 5-level inverter with FACTS capability using modular multi-level converter (MMC) topology,” Proc. 2013 IEEE Int. Electr. Mach. Drives Conf. IEMDC 2013, pp. 1229-1234, 2013.

[19] A.U. Lawan, M. Student, H. Abbas, J. G. K. S. M, and A. A. Karim, "Dynamic performance of Improvement of MMC Inverter with STATCOM Capability interfacing PMSG Wind Turbines with Grid," 2015 IEEE Conf. Energy Convers., pp. 492-497, 2015.

[20] A.U. Lawan, M. Mustapha, I. Abubakar, M. Mustapha, and I. Abubakar, "Reactive current control of STATCOM based MMC Inverter for Wind Turbines connected to Grid," 2015 IEEE Student Conf. Res. Dev., pp. 26-31, 2015.

[21] Historically, "Decoupled Control of Modular Multilevel Converters Using Voltage Correcting Modules," IEEE Trans. POWER Electron., vol. 30, no. 2, pp. 690-698, 2015.

[22] R. Lizana, S. Member, M. A. Perez, S. Member, D. Arancibia, J. R. Espinoza, and J. Rodriguez, "Decoupled Current Model and Control of Modular Multilevel Converters," IEEE Trans. Ind. Electron., vol. 62, no. 9, pp. $5382-5392,2015$. 
[23] W. Kawamura, M. Hagiwara, and H. Akagi, "Control and experiment of a modular multilevel cascade converter based on triple-star bridge cells," IEEE Trans. Ind. Appl., vol. 50, no. 5, pp. 3536-3548, 2014.

[24] M. Hagiwara, R. Maeda, and H. Akagi, "Control and analysis of the modular multilevel cascade converter based on double-star chopper-cells (MMCC-DSCC)," IEEE Trans. Power Electron., vol. 26, no. 6, pp. 1649-1658, 2011.

[25] L. Haw, M. S. a Dahidah, and H. a F. Almurib, "SHE-PWM Cascaded Multilevel Inverter With Adjustable DC Voltage Levels Control for STATCOM Applications," Power Electron. IEEE Trans., vol. 29, no. 12, pp. 6433 6444,2014

[26] S.A. Azmi, G. P. Adam, K. H. Ahmed, S. J. Finney, and B. W. Williams, "Grid interfacing of multimegawatt photovoltaic inverters," IEEE Trans. Power Electron., vol. 28, no. 6, pp. 2770-2784, 2013.

[27] M. Zhang, L. Huang, W. Yao, and Z. Lu, "Circulating harmonic current elimination of a CPS-PWM-based modular multilevel converter with a plug-in repetitive controller," IEEE Trans. Power Electron., vol. 29, no. 4, pp. 2083-2097, 2014.

[28] M. Hagiwara, K. Nishimura, and H. Akagi, "A medium-voltage motor drive with a modular multilevel PWM inverter,” IEEE Trans. Power Electron., vol. 25, no. 7, pp. 1786-1799, 2010.

[29] J. I. Y. Ota, Y. Shibano, and H. Akagi, "A Phase-Shifted PWM D-STATCOM Using a Modular Multilevel Cascade Converter ( SSBC ) - Part II : Zero-Voltage-Ride-Through Capability,” IEEE Trans. Ind. Appl., vol. 51, no. 1, pp. 289-296, 2015.

[30] J. I. Y. Ota, Y. Shibano, N. Niimura, and H. Akagi, "A Phase-Shifted-PWM D-STATCOM Using a Modular Multilevel Cascade Converter (SSBC): Part I. Modeling, Analysis, and Design of Current Control,” IEEE Trans. Ind. Appl., vol. 9994, no. c, pp. 1-1, 2014.

[31] K. H. Law, "New Current Control Algorithm Incorporating Multilevel SHE-PWM Approach for STATCOM Operation under Unbalanced Condition," Power Electron. Distrib. Gener. Syst. (PEDG), 2014 IEEE 5th Int. Symp., pp. 1-7, 2014.

[32] D. E. Soto-Sanchez, R. Pena, R. Cardenas, J. Clare, and P. Wheeler, "A cascade multilevel frequency changing converter for high-power applications," IEEE Trans. Ind. Electron., vol. 60, no. 6, pp. 2118-2130, 2013.

[33] R. Majumder, "Reactive Power Compensation in Single Phase Operation of MicroGrid," IEEE Trans. Ind. Electron., vol. 60, no. 4, pp. 1403-1416, 2012.

[34] M. Miranbeigi, Y. Neyshabouri, and H. Iman-Eini, "State feedback control strategy and voltage balancing scheme for a transformer-less STATic synchronous COMpensator based on cascaded H-bridge converter," IET Power Electron., vol. 8, no. 6, pp. 906-917, 2015.

[35] Oates and G. Mondal, "DC circulating Current for Capacitor Voltage Balancing in Modular Multilevel Matrix Converter," Proc. 2011 14th Eur. Conf. Power Electron. Appl., pp. 1-6, 2011.

[36] W. L. Chen and C. Z. Xie, "Active voltage and frequency regulator design for a wind-driven induction generator to alleviate transient impacts on power grid," IEEE Trans. Ind. Electron., vol. 60, no. 8, pp. 3165-3175, 2013.

[37] H. Daniyal, E. Lam, L. J. Borle, and H. H. C. Iu, "Hysteresis, PI and Ramptime Current Control Techniques for APF: An experimental comparison," Proc. 2011 6th IEEE Conf. Ind. Electron. Appl. ICIEA 2011, pp. 21512156, 2011.

[38] AU Lawan, HAF Almurib, JG Khor, S Babani "Circulating Current control of a Modular Multilevel Converter (MMC) with State Feedback Controller and Harmonic Current Suppression " 2018 IEEE International Conference on Electrical Systems for Aircraft, Railway, Ship Propulsion and Road Vehicles \& International Transportation Electrification Conference (ESARS-ITEC), pp 1-8, 2018.

[39] Syed Zulqadar Hassan, Hui Li, Tariq Kamal, Ali Arsalan, Abdurrahman Umar Lawan "Performance of gridintegrated Wind/Microturbine/battery Hybrid renewable power system" Power and Energy (PECon), 2016 IEEE International Conference,pp 78-83, 2016.

[40] Abubakar Abdulkarim, Sobhy Mohammed Abdelkader, D John Morrow, Falade John Alaba, Abdurrahman Umar Lawan, HR Iswadi "Effect of weather and the hybrid energy storage on the availability of standalone microgrid" International Journal of Renewable Energy Research (IJRER), Vol. 6, no. 1, pp. 189-198, 2016.

[41] Abdurrahman Umar Lawan, Haider A.F. Almurib, Jeen G. Khor "Enhanced decoupled Current Control with Voltage Compensation for Modular Multilevel Converter (MMC) based STATCOM" International Journal of Power Electronics and Drives System (IJPEDS), Vol. 10, no. 3, pp. 24-25, 2019. 